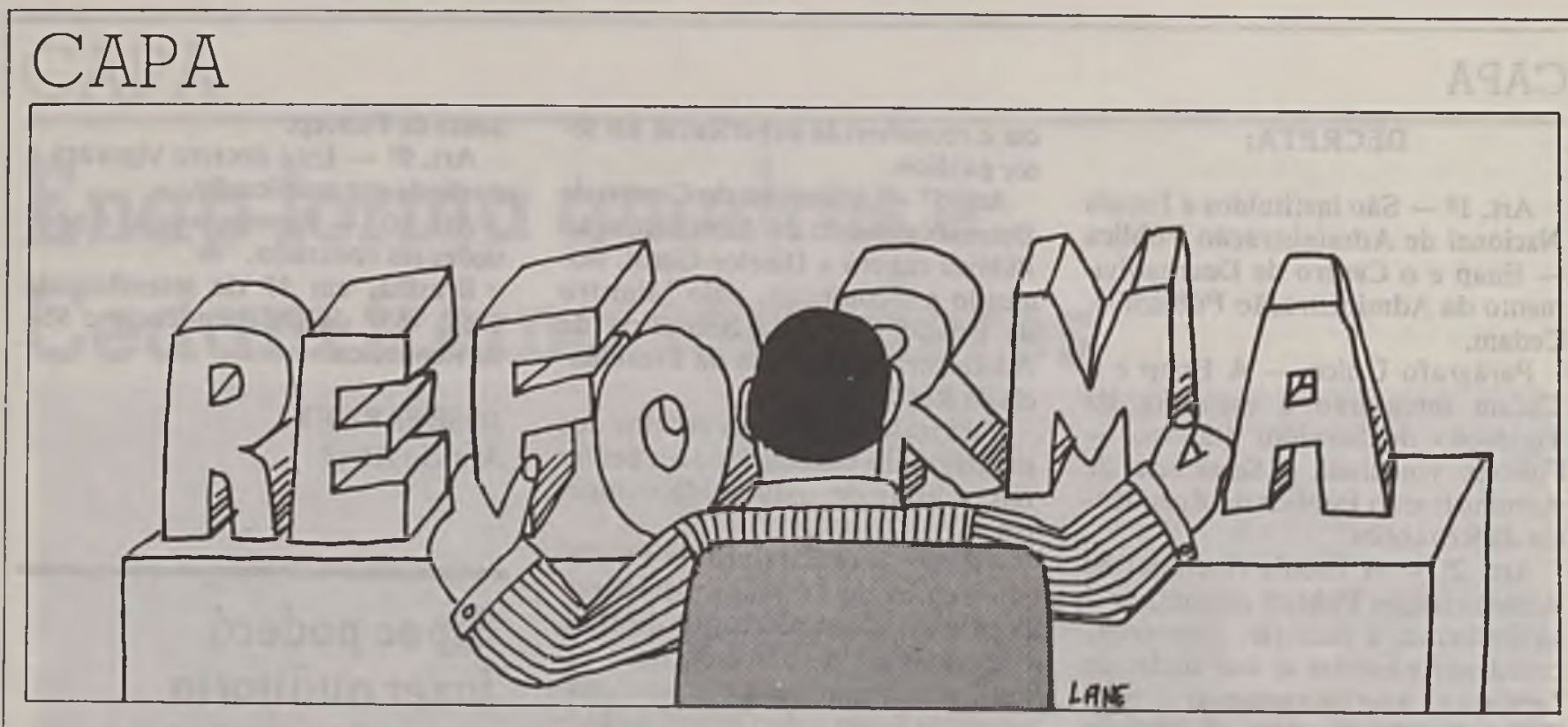

\section{0 estatuto finalizado vai ao exame do Presidente Sarney}

O próximo passo da Reforma Administrativa será a finalização do Estatuto do Servidor Público, que definirá o novo regime jurídico e o novo plano de carreira para o funcionalismo público federal. $\mathrm{O}$ documento deverá estar concluido ao longo de outubro, para encaminhamento ao presidente Sarney, que decidirá sobre seu envio ao Congresso Nacional, em forma de projeto de lei.

O Estatuto, segundo o Ministro Aluizio Alves, "acabará com o apadrinhamento para ingresso no servico público".

As novidades são:

- Os servidores concursados serdo automaticamente enquadrados no novo regime jurídico $\mathrm{c}$ no plano de carreira.

Outros itens futuros da reforma - Como desdobramentos da Refor-
* Os que não prestaram concurso para o serviço público, incluindo os 106 mil servidores das tabelas especiais, recém-enquadrados, serão obrigados a fazê-lo.

* Não haverá, portanto, demissão de qualquer servidor público, mas seu reenquadramento, mesmo que se verifique cxcesso de pessoal.

* O servidor terá a opção de fazer ou não o concurso, mas se assim o preferir, não o fazendo, ficará lotado $\mathrm{cm}$ um quadro em extinção, sem dircito a fazer carreira no serviço público.

* A carreira vai ser fundamentada no sistema do mérito,e seu acesso só se dará por concurso.

* Através dos concursos, o funcionário poderá chegar até a vicedirctor de um órgão, começando até mesmo de contínuo.

ma Administrativa, serão ultimados nas próximas etapas.

- Senapro - Serviço Nacional de vendo ser instituido em toda a estruProtocolo, que permitirá a qualquer tura governamental, após a bem cidadão brasileiro o acesso ao anda- sucedida experiência-piloto na Semento de seu processo, requerimen- cretaria de Administração Pública to ou solicitação administrativa, de- da Presidência. 


\section{Pagamento do pessoal terá uma folha única para evitar abusos}

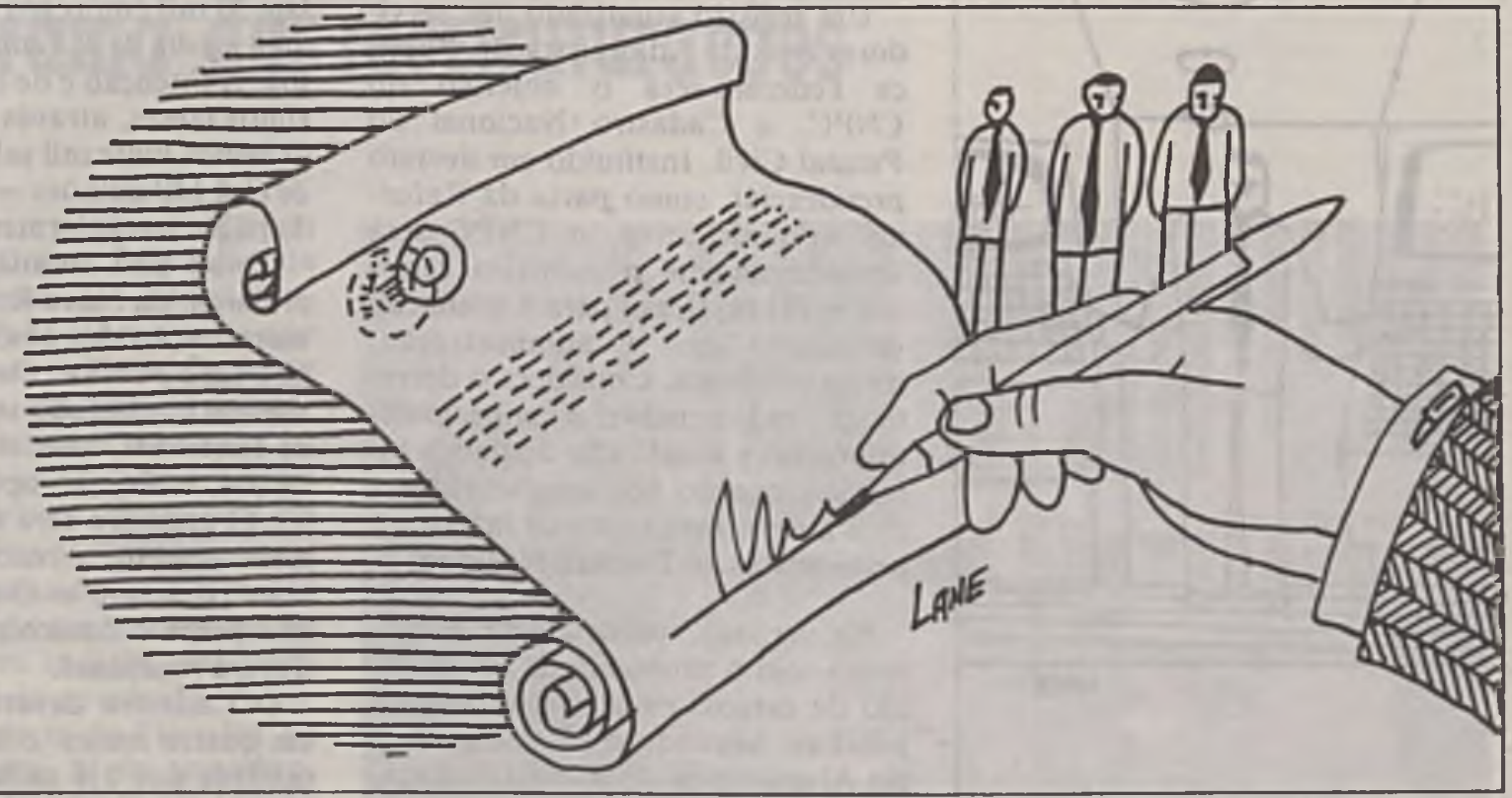

O controle do sistema de pagamentos do Governo, via Secretaria do Tesouro Nacional (STN), lhe permitirá, pela primeira vez, ter um conhecimento de sua folha global, hoje uma impossibilidade pela diversificação de fontes, modelos e critérios. Um dos decretos da Reforma Administrativa, a criação da fotha única, permitirá que o pagamento seja sistematizado e padronizado, para que todo o universo dos funcionários públicos tenha um tratamento único na administração direta e indireta.

O controle do sistema de pagamentos deverá estar concluído em quatro meses, e operará através da STN como um coibidor das distorç̃es usuais do serviço público, nas quais se inclu 1 a acumulaça indevida de cargos. Pela centralização dos pagamentos, o Governo terá uma visão geral das folhas e não permitirá que se mantenham as irregularidades usuais.

A padronização dos pagamentos também implicará um drástico barateamento dos processos administrativos de pagamentos, pois dará um modelo único para as folhas. Esses procedimentos hoje divergem quanto á natureza e ao custo: se- rão, por isso, adequados todos os sistemas de informações e regras de comportamento aos novos modelos da STN, para que todo o mecanis-

\section{Advocacia Consultiva dará coerência aos atos}

Preocupava o Governo o problema da legalidade dos atos jurídicos do Estado, praticados pela ação estatal observando a um sem- número de critérios e modelos de comportamento. Com a visáo da necessidade da unificação desses padrðes, para que sejam aperfeiçoados os mecanismos de controle interno da legalidade da ação do Estado, foi criada a Advocacia Consultiva da Uniāo.

Parte fundamental da Reforma Administrativa, a Advocacia da União cuidará da regulação e adoção de coerência e unidade doutrinárias às atividades dos órgãos de consultoria e assessoramento juridico da União, e das entidades vinculadas.

A Advocacia Consultiva da União compreende a ConsultoriaGeral da República, a mo de pagamentos do Governo ao seu pessoal civil, inativos e pensionistas do Tesouro, se ajuste a uma só norma.

Procuradoria-Geral da Fazenda $\mathrm{Na-}$ cional; no Ministério da Fazenda; as consultorias juridicas dos demais ministérios, do EMFA, da Seplan e da Sedap, como também as procuradorias-gerais ou os departamentos jurídicos das autarquias, órgãos juridicos das empresas públicas, sociedades de economia mista, fundações sob supervisão ministerial e demais entidades controladas, direta ou indiretamente, pela Uniāo.

Todas terão que seguir novos preceitos no zelo pela observância da Constituição, das leis e dos tratados, bem como dos atos emanados da Administração Federal, cabendo à Advocacia Consultiva da União fixar a interpretação desses textos legais, e assistir o Presidente da República no controle interno da legalidade dos atos praticados pela Administraçăo Pública. 


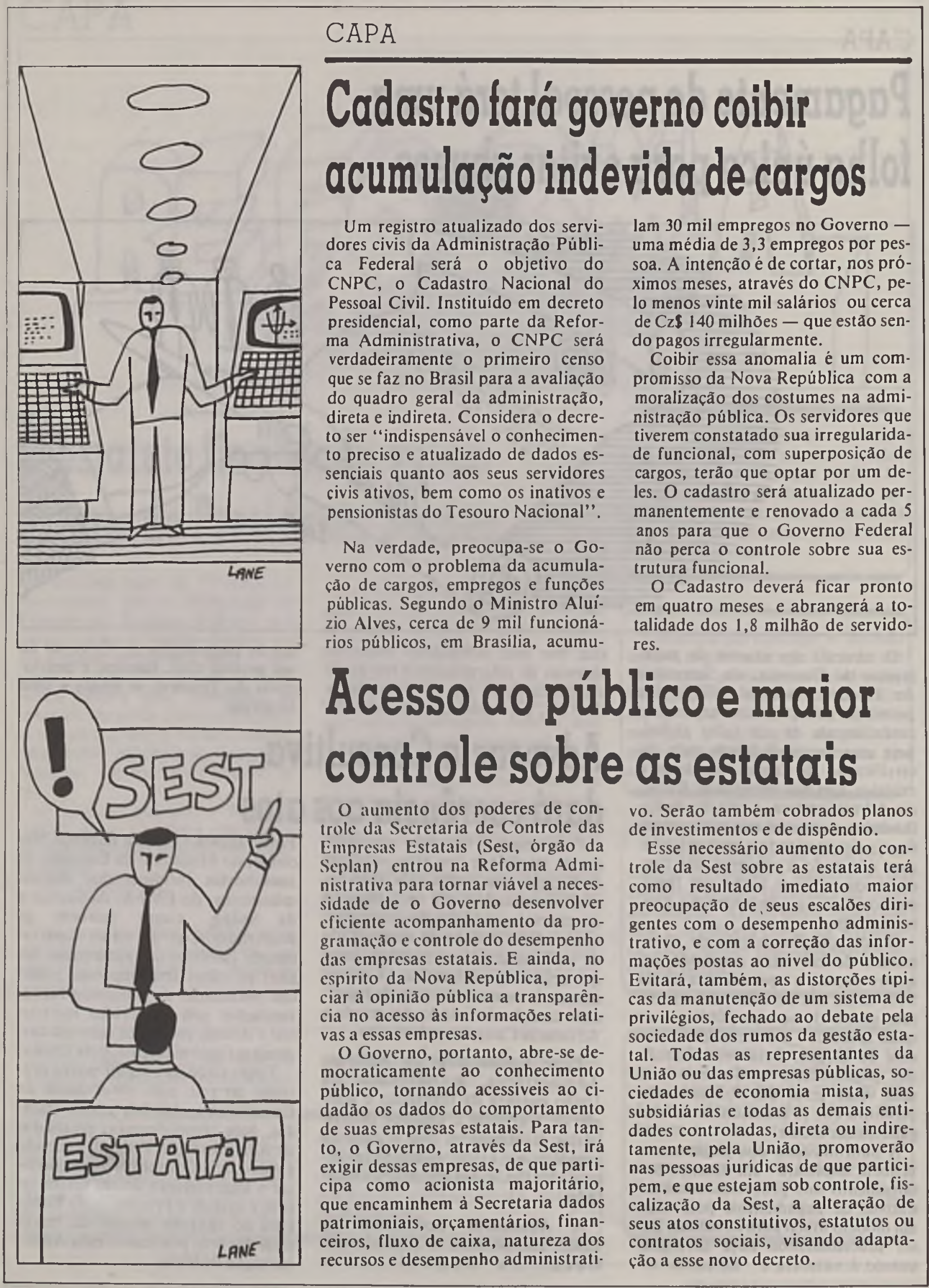




\section{GERAP já se reuniu e traçou cronograma das reestruturações}

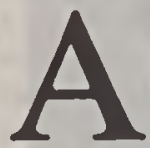
primeira reunião do $\mathrm{Ge}$ rap (Grupo Executivo da Reforma da Administra. (ão Pública) mostrou que os 5 ministros aos quais o presidente Sarney atribuiu, em decreto assinado, a responsabilidade da execução das medidas em lodos os ministérios e órgãos do Cioverno, têm pressa em colocar em prálica as medidas.

O Gerap é presidido pelo ministro Aluizio Alves, e suas reuniōes serão freqüentes, e em rodizio, nas sedes de cada ministério envolvido. A primeira foi no Palácic do Planalto, na última terça-feira, 23 de setembro, depois de ter sido adiada em função da viagem do ministro da Fazenda, Dilson Funaro, aos Estado Unidos e Europa.

Integram o Gerap, segundo o decreto presidencial, os ministros Aluizio Alves) (SEDAP) Dilson Funaro (Fazenda), João Sayad (Planejamento), Marco Maciel (Gabinete Civil) e Almir Pazzianotto('Trabalho).

Decisōes da reunião - Na primeira reunião foram apreciados os prazos e cronogramas para a estruturação. dos ministérios em função da Reforma Administrativa nos setores de pessoal.. Foram também avaliadas as situaçōes dos atuais quadros de pessoal existentes, a merecerem um amplo reenquadramento e, como o ministro-chefe da Sedap já garantiu, sem demissð̄es de servidores.

O grupo de trabalho interministerial também tratou dos remanejamentos de pessoal que serão feitos. sendo o primeiro caso, mais premente, o do Ministério da Industria e do Comércio, que vai colocar à disposiçâo do Gerap cerca de $7 \mathrm{mil}$ e 100 funcionários, considerados ociosos pelo Instituto Brasileiro do Café (IBC), Instituto do Açúcar e do Álcool (IAA) e Superintendência

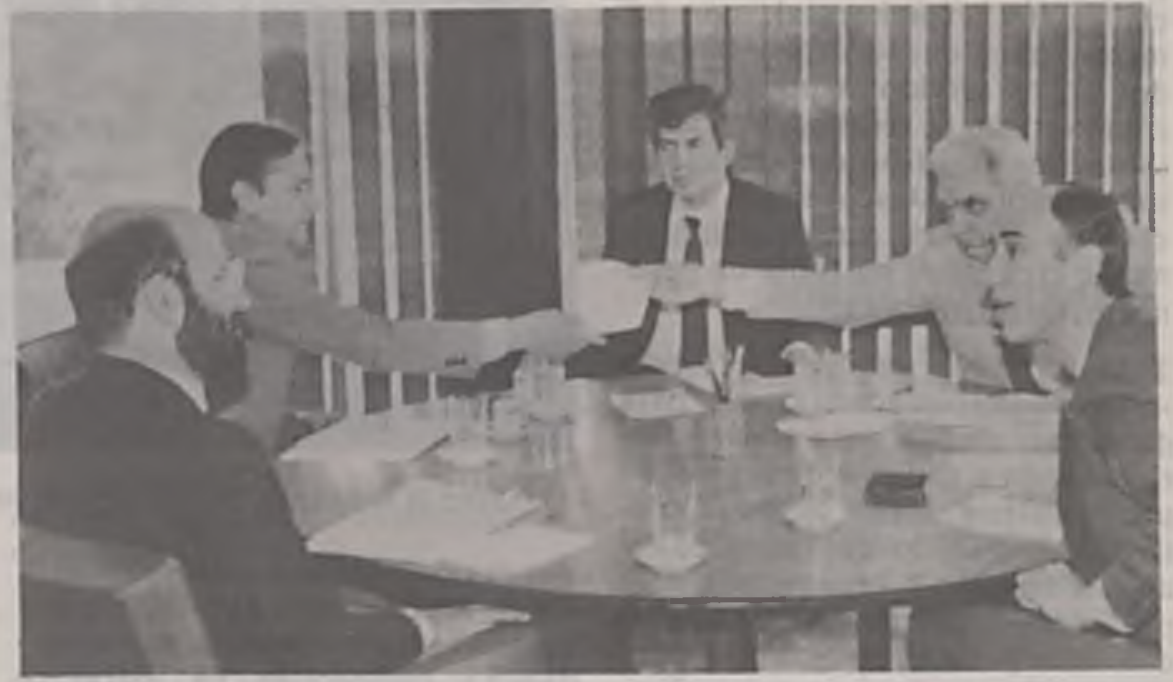

Sayad, Funaro, Pazzianoto, Aluizio e Maciel, o Gerap

Nacional da Borracha (SUDHEVEA).

Para esses casos - os do MIC, e dos demais ministérios que colocarão pessoal em disponibilidade - a Sedap se incumbirá de identificar os niveis funcionais, e realizar a triagem dos servidores para os setores governamentais que mais necessitam de quadros, como a SUNAB e a LBA.

O sistema de Pessoal Civil da Sedap examinará todos os casos, pesquisará as aspirações de cada servidor disponivel em função de seu futuro funcional, e thes oferecerá a nova atribuiçãol, em outro órgão, depois de convenientemente reciclados, para absorverem a nova tarefa no serviço público. O governo, inclusive, Ihes oferecerá opçōes de mudança para outros estados pois o serviço público está congestionado entre Brasilia e o Rio de Janeiro - enquanto outros estados apresentam carências de quadros.

Alé mesmo para a iniciativa privada esses servidores postos à disposição por seus ministérios poderão ser remanejados, numa possibilidade aberta pelo governo, que estuda esse incentivo para que seus quadros sejam enxugados. Nesse sentido, haveria a possibilidade de o funcionário que se demitir ir para a iniciativa privada receber de seis meses a um ano de salário, como estimulo.

Respeito ao funcionário - Todas as medidàs a serem executadas para reestruturaçao da máquina administrativa serão fundamentadas no respeito a condiça humana e profissional do funcionário. Não foi por culpa deles que o serviço público inchou, nas últimas décadas, tornando-se uma máquina burocratizada e inerte. Tudo foi obra de administraçōes anteriores que nomeavam, sem critério, um número absurdo de funcionários, apenas pelo exercício do apadrinhamento.

Os servidores considerados excedentes, portanto, teråo todo direito à escolha. Primeiramente, ficarão em casa, recebendo seu salário, por um mês, para poderem refletir sobre seu futuro funcional. Nesse periodo receberào a visita de representantes 
da Sedap para preenchimento de um questionário que mostrará suas aptidões e aspiraçðes de mudança para outros estados em que sobram vagas.

Com a redistribuição, feita pelo Sistema de Pessoal Civil da Sedap, serão transferidos para outros órgãos, não sem antes passarem por um periodo de reciclagem e treinamento de dez dias, em Brasilia, na Funcep, para absorverem as novas funcões. Essa transferência se dará em caráter experimental, por três meses, para que o órgão receptor dos novos servidores possa avaliar com exatidão os resultados da adaptação dos quadros remanejados à sua estrutura. Depois dessa avaliação, em 3 meses, serão definitivamente efetivados na folha de pagamento do novo órgão.

As próximas reunioes do Gerap - Em cada reunião do Gerap, para que se tornem práticas e eficazes, será avaliada a situação de pessoal de um ministério. Nessa primeira, efetivada no Palácio do Planalto, foi apenas traçado o cronograma e os prazosde'entrega de estudos acabados sobre pessoal, pelos ministérios. $\mathrm{Na}$ reunião seguinte, que se realizará nos primeiros dias de outubro, o caso a ser examinado será o do Ministério da Industria e do Comércio. Nas reuniōes semanais que se seguirão, entrarão em pauta os Ministérios da Previdência e Assistência Social, Cultura e Trabalho.

Em cada reunião, ser âo aprecia-

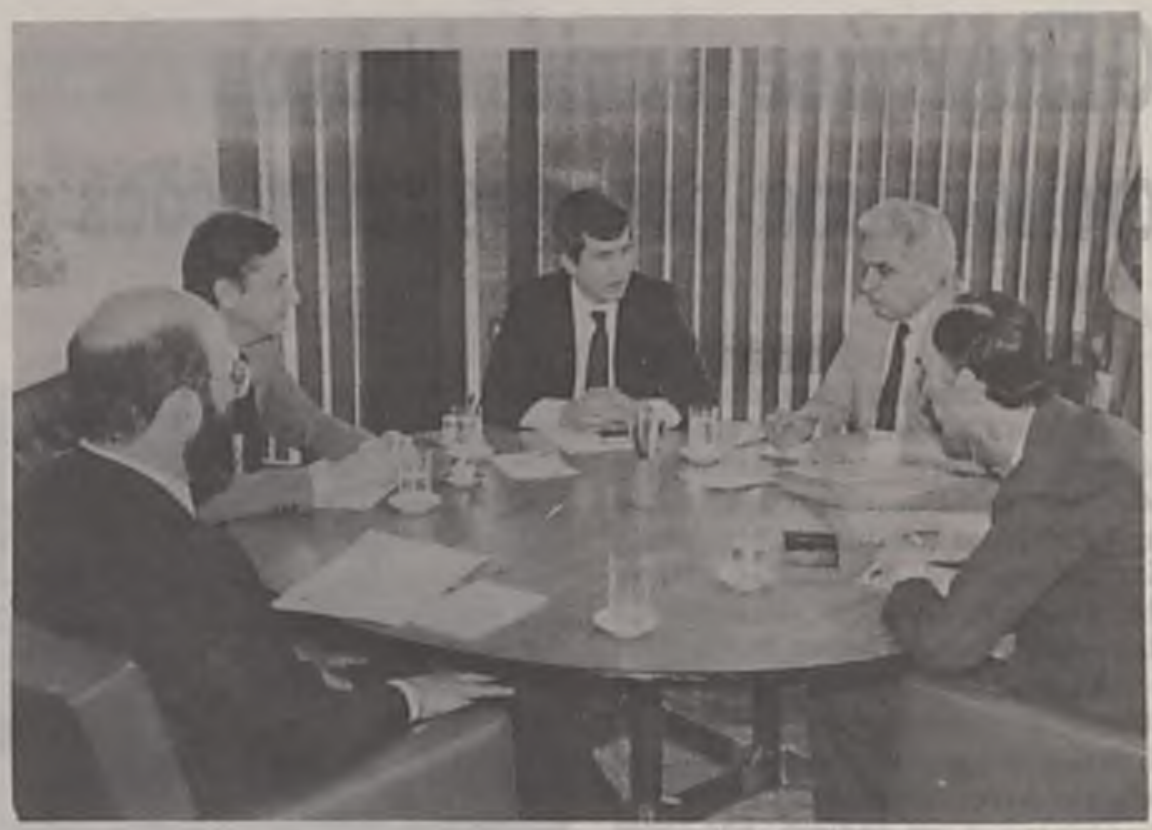

O Gerap já se reuniu, depois de criado

das as situações não só do ministério $\mathrm{cm}$ si, mas de todas as estatais e autarquias a ele vinculadas, numa verdadeira radiografia da estrutura funcional para identificação de supirfluos e excedentes. Cada ministério terá aprovada pelo Gerap sua nova estrutura administrativa, readaptando-os ao espirito dos decretos assinados pelo Presidente da República, implantando o início da Reforma Administrativa do goverII).
Num prazo de 90 dias, todo o governo estará reestruturado com o Gerap decidindo também que órgãos públicos serão extintos, incorporados a outros, ou simplesmente fundidos a terceiras entidades, numa tentativa de racionalização da estrutura da administração direta e indireta, barateando o custeio da União com a administração pública, e promovendo maior agilidade e eficiência na operação do setor governamental.

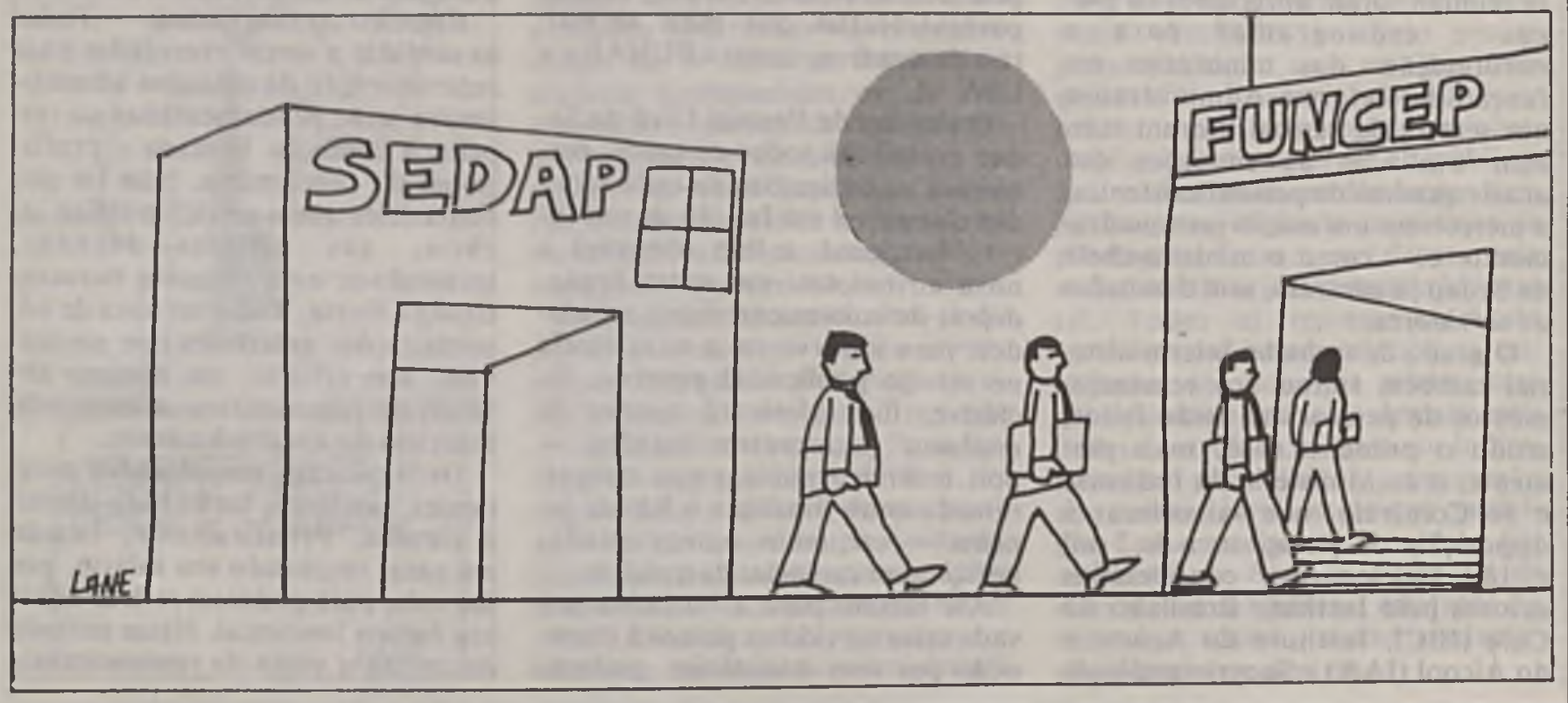

